\title{
SOBRE LA PRETENDIDA CORRECCIÓN DE LA PRETENSIÓN DE CORRECCIÓN
}

s bien conocido que los escritos de H. L. A. Hart abrieron nuevas perspectivas desde las que afrontar el problema de las relaciones entre el derecho y la moral. Uno de los méritos indudables de su obra radica en su esfuerzo por dar respuesta a lo que él mismo calificó como «una tarea central de la filosofía del derecho», la de explicar la fuerza normativa de las proposiciones jurídicas (Hart, 1983, pág. 18). Planteaba así el problema de conciliar dos perspectivas necesarias para una descripción completa de la existencia y funcionamiento de un sistema jurídico. De una parte, la percepción del derecho como un conjunto de hechos sociales complejos permite a un observador dar cuenta de los mismos mediante juicios descriptivos valorativamente neutros. Por otro lado, la actitud de quienes recurren característicamente al lenguaje normativo para expresar su aceptación del derecho -o de sus normas constitucionales fundamentales- y ven en las reglas que lo integran una guía de sus propias acciones y un criterio para evaluar críticamente las acciones de los demás. Hart insiste en que si la forma ordinaria de describir el contenido del derecho es a través de proposiciones que recurren a un vocabulario normativo que incluye términos como «obligación», «deber», o «derecho», el problema de la normatividad del derecho consiste -al menos, en parte- en explicar este uso característico del lenguaje normativo sin abdicar de la tesis positivista de la separación conceptual entre el derecho y la moral (Hart, 1982, págs. 144-7).

Sin embargo, la conocida distinción hartiana parece haber desplegado una mayor fuerza a la hora de sustentar argumentaciones que, a propósito del concepto de derecho, niegan la tesis de la separación y afirman que existe una vinculación de tipo conceptual entre el derecho y la moral. La conexión entre derecho y moral suele así, paradójicamente, ser presentada como una consecuencia del modelo explicativo que Hart había propuesto acerca del concepto de derecho. En un iluminador trabajo, publicado recientemente, 
Garzón Valdés (1996, págs.397-424) explora las posibilidades básicas concebibles por lo que respecta a la relación entre el derecho y la moral organizándolas de acuerdo con las mencionadas tesis de la separación y tesis de la vinculación. Entre las versiones más significativas que defienden la idea de la conexión conceptual figuran aquellas que conceden a la pretensión de corrección del derecho una relevancia esencial. Según Garzón, esta posición sostiene que «si se quiere dar cuenta del funcionamiento de un sistema de derecho positivo, no es posible ignorar pretensiones normativas morales que van más allá de la mera positivación jurídica de una moral positiva, ya que aspiran a ser correctas también desde la perspectiva de una moral crítica o ética» (1996, págs. 399-400). Bajo este planteamiento general, y reconociendo que parten de enfoques diferentes, Garzón Valdés se refiere tanto al argumento de la pretensión de corrección defendido por R. Alexy, como al argumento de la pretensión de legitimidad defendido por él mismo en este y otros escritos (1990, págs. 111-130). En general, la posición que agrupa estos puntos de vista, opina Garzón, puede entenderse que es complementaria de aquella otra que adopta como estrategia argumentativa una relación de equivalencia entre «punto de vista interno» y «punto de vista moral»: Dado que las razones para obedecer al derecho solo pueden ser prudenciales o morales, y puesto que el punto de vista externo representa el caso de quien adopta razones prudenciales, el punto de vista interno parece implicar una adhesión a las normas del derecho por razones morales. Si como se ha recordado al principio el punto de vista interno fue considerado por Hart como un elemento necesario a la correcta descripción del concepto de derecho, la tesis de la vinculación conceptual quedaría establecida al poder así afirmar, como hace Garzón, que «todo enunciado de existencia de un sistema jurídico positivo presupondría la existencia de un punto de vista moral» (1996, pág. 399). Desde un planteamiento de este tipo todo observador externo carecería de la posibilidad de identificar lo que es derecho si a su vez no admite la coincidencia de éste con las creencias morales de quienes son participantes comprometidos con el sistema. Ello no significa, sin embargo, que este observador externo no pueda tachar de errónea esa pretensión de legitimidad si su idea de lo correcto desde el punto de vista de la moral crítica o ideal no coincide con el contenido de aquellas creencias que, al menos, sustenta la parte oficial del sistema. Así, según Garzón Valdés: «Es obvio que sus "proposiciones morales internas" [las del observador] pueden no coincidir con las de quienes aceptan e imponen el sistema objeto de su consideración. Pero de aquí no se sigue sin más que necesariamente deba negar el carácter jurídico al sistema que considera. De la negación de la tesis de la neutralidad, no se sigue que no pueda calificarse a un sistema jurídico existente como inmoral» (1990, pág. 122). 
En suma, la aceptación de la tesis de la vinculación conceptual es, desde la argumentación ahora brevemente descrita, necesaria para una correcta descripción del concepto de derecho. En lo que sigue voy a analizar algunos de los inconvenientes que, a mi juicio, aquejan a este tipo de propuestas. El argumento de la corrección puede ser abordado críticamente desde dos perspectivas: (i) la de su fundamentación. En el caso de Alexy, quien quizá representa el esfuerzo más notorio en esta dirección, se da una remisión clara a la ética discursiva tal como ésta es expuesta por Habermas. Creo que ello presenta inconvenientes y me referiré a algunos de ellos; (ii) la de su trivialidad; el argumento de la corrección, y así lo reconoce el propio Alexy, si bien puede mostrar una conexión conceptual entre el derecho y la moral puede ésta ser atacada por la vía de que su contenido es trivial y sus implicaciones morales prácticamente nulas. Sospecho que también este tipo de crítica puede ser acertada.

\section{I}

Los planteamientos a los que he aludido parecen compartir una misma idea: las diferentes denominaciones -pretensión de corrección, de legitimidad, de sinceridad por parte de las autoridades normativas- son expresiones equivalentes para dar cuenta del punto de vista interno. Quien lo adopta formula necesariamente una pretensión de corrección ética. El de participante se configura así como un concepto clave en la configuración de aquella perspectiva desde la que establecer una conexión conceptual entre el derecho y la moral. El marco conceptual que precisa la pretensión de corrección se completa, según Alexy con las nociones de procedimiento - «como sistema de procedimientos, el sistema jurídico es un sistema de acciones basadas en reglas y guiadas por ellas, mediante las cuales se crean, se justifican, se interpretan, se aplican y se coaccionan normas»-, e ideal, en tanto que se basa en el supuesto de que los ideales jurídicos se hallan incluídos en la realidad de un sistema jurídico. El no positivista que quiera demostrar la existencia de una conexión conceptual necesaria desde la perspectiva ahora aludida deberá, a juicio de Alexy, «mostrar cómo en los procesos de creación y aplicación del derecho los participantes tienen, necesariamente, una pretensión de corrección, la cual incluye una pretensión de corrección moral» (1989, pág. 45). Las posibilidades teóricas de establecer tal vinculación entre el derecho y la moral son numerosas. Alexy limita la multiplicidad de tesis a la aceptación de dos requerimientos: (i), que la vinculación establecida revele una conexión conceptual necesaria; y (ii), que la noción de derecho empleada en la argumentación incluya el concepto de validez, lo cual supone la toma en consideración, a la hora de discutir el positivismo jurídico del contexto institucional de promulgación, aplicación y coacción del derecho. 
El llamado por Alexy «argumento de la corrección» engloba las razones en favor de la tesis recién esbozada. La otra posibilidad que explora Alexy, y de la que no habré de ocuparme aquí, ofrece un marco de análisis delimitado por la noción de derecho entendido ahora como sistema de normas, contemplado por quien adopta la perspectiva del observador, y que trata de establecer una conexión definitoria, esto es, aquel tipo de vinculación conceptual entre el derecho y la moral por la que a una norma o a un sistema de normas que no satisfacen cierto criterio moral se les niega su carácter jurídico. Quien quiera argumentar en este sentido deberá demostrar que traspasado cierto umbral de injusticia las normas o sistemas de normas pierden su carácter jurídico. La conexión presuntamente establecida aquí sería, efectivamente, de carácter conceptual tal como se requería en el enunciado (i) expuesto más arriba, ya que la satisfacción del requerimiento moral se presenta como necesaria. Las razones en favor de esta tesis son englobadas en lo que Alexy, en referencia a Dreier, denomina «argumento de la injusticia».

La teoría de la corrección, sin embargo, puede poner de manifiesto bien una conexión de tipo definitorio -si los sistemas de normas no contienen ni explícita ni implícitamente esa pretensión de corrección no son sistemas jurídicos-, o bien un segundo tipo de conexión que Alexy denomina calificativa que se establece cuando una norma o sistema de normas que no satisfacen cierto criterio moral pueden ser considerados normas jurídicas o sistemas jurídicos aun cuando se pueda decir que son defectuosos por razones no sólo morales sino también conceptuales. Así puede decirse que un sistema jurídico que contiene una pretensión de corrección pero no la satisface es un sistema jurídico defectuoso. En relación a las normas individuales y las decisiones judiciales la conexión que viene a mostrar el argumento de la corrección es siempre calificativa; «éstas son jurídicamente defectuosas cuando no tienen, o no satisfacen, la pretensión de corrección» (Alexy, 1989, pág. 52). Como ha señalado E. Bulygin la conexión calificativa parece mostrar así un carácter meramente fáctico; si para su establecimiento no se requiere necesariamente la satisfacción del criterio moral que expresa la pretensión de corrección, entonces la conexión no es una conexión conceptual o analítica, sino sintética o fáctica (Bulygin, 1993, pág. 20). Lo cual no cumpliría la limitación prevista por Alexy en (i) acerca de la clase idónea de argumentos para establecer la vinculación entre el derecho y la moral.

La pretensión de corrección implica pretensión de justificación. En el caso de Alexy las exigencias de igualdad y universalidad que plantea toda pretensión de justificación provienen de la base de una ética procedimental que se construye sobre la idea de generalizabilidad (Alexy, 1989, pág. 55). Ésta es la ética discursiva, que en la versión de Habermas, versión que, como 
es sabido, es la adoptada por Alexy, descansa sobre una fundamentación pragmático universal o pragmático trascendental. El nivel pragmático de la fundamentación radica en la pretensión de corrección de los actos de habla regulativos que se establece con el recurso a la teoría consensual de la verdad cuya fundamental consecuencia se traduce en la posibilidad de «equiparar proposiciones normativas y no normativas, en cuanto a su capacidad de verdad» (Alexy, 1978, pág. 113). Se produce así un desplazamiento del concepto de verdad desde el nivel de la semántica al de la pragmática que permite formular las proposiciones normativas en términos de verdad o falsedad y establecer un tratamiento simétrico entre la pretensión de validez (de verdad) de un acto de habla constatativo y la pretensión de validez (de corrección) de un acto de habla regulativo. El razonamiento correría de la siguiente forma: del mismo modo que una proposición descriptiva incorpora necesariamente una pretensión de verdad que convierte en contradictorio enunciados como el del ejemplo de Austin («el gato está sobre el felpudo pero yo no lo creo») también una proposición prescriptiva incorpora una pretensión de corrección cuya ausencia manifiesta un defecto que resulta relevante no solo en el plano moral. De forma que la pretensión de corrección, constitutivamente incorporada a los actos de habla regulativos, no solo representa una condición de éxito de éstos; también una condición del propio juego del lenguaje, de las reglas que están en la base de los actos de habla (Alexy, 1978, págs. 134, 318). La contradicción, de carácter performativo, se traduce así en la incompatibilidad entre lo que se prescribe a través de un acto de habla y las reglas que rigen tal acto de habla. Ello muestra que los participantes en un sistema jurídico, en los diferentes niveles, tienen necesariamente una pretensión de corrección. Pero que esta pretensión de corrección pueda llevar justificadamente al establecimiento de una conexión conceptual del derecho con la moral depende de lo que pueda aportar la teoría del discurso junto con la tesis del caso especial.

En términos parecidos se expresa Garzón Valdés para defender la vinculación conceptual del derecho con la moral y poder afirmar que las «autoridades y funcionarios se contradirían a ellos mismos si sostuvieran que la ética no juega ningún papel en el concepto de validez de las normas frente a las que adoptan un punto de vista interno» (1990, pág. 123), aun cuando falte en este caso una adhesión explícita a una fundamentación de tipo discursivo en cuyo centro gravita un concepto intersubjetivista de verdad que, como se ha señalado en el párrafo anterior, permite equiparar en cuanto a su capacidad de verdad, a proposiciones normativas y no normativas. Aun así, el defendido por Garzón no resulta en absoluto lejano a este tipo de planteamientos cuando se afirma, por ejemplo, que «con la pretensión de legitimidad sucede lo mismo que con la pretensión de verdad que sustenta 
quien afirma creer en la verdad de una proposición descriptiva» (1990, pág. 121). En un trabajo reciente E. Bulygin ha objetado precisamente el concepto de verdad que parece desprenderse de la posición defendida por Ernesto Garzón. De acuerdo con Bulygin no es aceptable, al menos desde el concepto de verdad que maneja la teoría de la verdad como correspondencia, que diferentes puntos de vista, los adoptados en el caso que nos ocupa por observadores y participantes, puedan afectar el valor de verdad de un determinado enunciado. $\mathrm{O}$ dicho con otras palabras, que la proposición acerca de que la ética, o moral crítica no juega ningún papel en la definición del concepto de derecho (Garzón, 1996, págs. 123/4), pueda resultar verdadera o falsa en función de la perspectiva adoptada, punto de vista externo o interno, por quien formula el enunciado que la expresa. Si se acepta que el valor de verdad de una proposición viene determinado de manera objetiva, es decir por su correspondencia con la porción de realidad a la que se alude en la oración, entonces la actitud subjetiva de quien la enuncia nada tiene que ver en tal determinación. Si por el contrario, el valor de verdad no se hace depender del objeto referido, sino de los sujetos que formulan la oración, entonces probablemente se está recurriendo a un concepto de verdad distinto. Es lo que, según Bulygin, no queda claro en el planteamiento que defiende Garzón (E. Bulygin, 1998, págs. 217/18).

Tampoco parece diferir mucho de las posiciones anteriores la que parece defender Soper cuando afirma que «los sistemas jurídicos son caracterizados esencialmente por la creencia en el valor, por la pretensión de buena fe de aquellos que formulan las normas de que lo hacen en interés de todos» (1984, pág. 95), si bien al hacer depender la validez de la norma de una determinada actitud o intención de la autoridad que la emite -la sincera creencia en su justicia o en su contribución al bien común- no precisa sustentarse en una metaética cognoscitivista. Hablar de pretensión de corrección sí requiere a mi juicio, en cambio, el apoyo de una posición metaética descriptivista.

La teoría ética de Alexy es la teoría del discurso. El núcleo de su argumentación puede ser glosado a partir de dos principios (E. Hilgendorf, 1995, pág. 184): (i) las cuestiones morales deben encontrar solución por medio de discusiones abiertas (discursos) a todos los concernidos, lo cual abre la posibilidad de que los participantes se esfuercen en alcanzar un acuerdo, y (ii), el contenido de (i) no es un mero postulado, sino que puede ser calificado de correcto en el sentido de una ética cognoscitiva. En su aplicación al derecho, sin embargo, la teoría del discurso suele ser presentada como una teoría procesal de la argumentación jurídica de acuerdo con la cual un enunciado normativo $\mathrm{N}$ es correcto si y solo si puede ser el resultado de un procedimiento $\mathrm{P}$ tal como éste es definido por las reglas del discurso. 
O lo que es lo mismo, como la expresión de una tesis de ética normativa que pretende guiar nuestras conductas de acuerdo con un procedimiento discursivo que garantiza una situación ideal de habla. La concepción ético discursiva diferencia, sin embargo, las normas que deben ser objeto de discusión y fundamentación de acuerdo con un procedimiento definido por las reglas del discurso, y las propias reglas del discurso que no pueden ser cuestionadas porque subyacen a la estructura del lenguaje y expresan de este modo la existencia de una moral correcta enraizada en nuestro propio lenguaje. Quien argumenta negando validez a las reglas que disciplinan el discurso incurre necesariamente en una contradicción que los defensores de la teoría califican de performativa (Alexy, 1978, pág. 313).

Sin embargo, la cuestión acerca de si una concepción pragmático trascendental suministra un fundamento último o un criterio de corrección objetivo a las reglas del discurso parece de difícil solución a la vista de lo que en esta dirección aportan tanto Habermas como Alexy. Creo que una respuesta insuficiente, como a mi juicio es la que se ofrece, convierte en insuficiente al argumento de la pretensión de corrección en orden a mostrar tanto una vinculación de la racionalidad jurídica con la teoría del discurso (tesis del caso especial) como un nexo conceptual entre el derecho y la moral.

En orden a mostrar la validez universal de las reglas de la argumentación, Alexy recurre a una versión débil del modo pragmático trascendental de fundamentación. Las diferencias respecto de Habermas pueden establecerse con cierta claridad si tomamos en cuenta su tesis principal acerca de que todo hablante une a sus manifestaciones las pretensiones de inteligibilidad, veracidad, corrección, y verdad. Y que quien emite un juicio de valor o de deber plantea necesariamente una pretensión de corrección, es decir, pretende que su afirmación es fundamentable racionalmente y susceptible, por tanto, de ser objeto de un consenso logrado gracias a una argumentación que se desarrolla bajo condiciones determinadas. Estas condiciones son constitutivas de toda práctica argumentativa; la renuncia a estos presupuestos priva a la argumentación de todo sentido ya que incurrimos en una contradicción pragmática. El proceso de fundamentación de los presupuestos de la argumentación acaba aquí. No hay alternativa: abstenerse de toda argumentación es autodestructivo, ya que nos introduce necesariamente en una suerte de existencial callejón sin salida (Habermas, 1983, pág. 128).

De acuerdo con lo anterior puede establecerse que el fin o telos del lenguaje es el entendimiento ( Verständigung»), es decir, «el proceso de consecución de un acuerdo sobre la base presupuesta de pretensiones de validez reconocidas en común» (Habermas, 1976, pág. 301). En cuanto praxis universal que se halla en la base de todo comportamiento humano no hay posibilidad de ignorar esta finalidad propia del lenguaje. La concepción 
pragmático universal nos asegura que aun quien no estuviera interesado en hacerse entender, en el sentido habermasiano del término, porque introdujera en el lenguaje que emplea el engaño o cualquier otra distorsión de los presupuestos discursivos no desmiente con ello este fin inherente al lenguaje.

En el caso de Habermas la fundamentación pragmática es universal, esto es, $a$ posteriori, porque recurre a la constatación empírica de la universalidad de la pretensión de corrección en los actos de habla regulativos a través de ciencias reconstructivas. En el caso del derecho se trata de que la racionalidad procedimental asegure, en palabras del filósofo alemán, «un momento de incondicionalidad y una estructura sustraída a ataques contingentes» (Habermas, 1988, pág. 37) ¿Cómo es posible esto? Si interpreto correctamente, el razonamiento requiere la defensa de un tipo de saber intuitivo, o preteórico, como lo denomina Habermas, que asistiría a toda persona en cuanto sujeto discursivamente capaz. En su trabajo titulado «¿Qué significa pragmática universal?» se nos ofrece una explicación de la tarea del intérprete a la hora de reconstruir el significado de una expresión. El objeto de la llamada comprensión reconstructiva no es ya el contenido de lo que un sujeto en una determinada situación haya podido querer decir, sino «la conciencia intuitiva de regla» («Regelbewusstsein») que un hablante competente tiene de su lengua. El autor de una emisión lingüística, en la medida en que su emisión es una emisión inteligible, la produce conforme a determinadas reglas y en virtud de determinadas estructuras, es decir, «(d)omina el sistema de reglas de su lengua y sabe cómo aplicarlo específicamente en cada contexto, tiene de ese sistema de reglas un saber preteórico que le permite en todo caso hacer la emisión o manifestación de que se trata». El intérprete, por su parte, que no solamente comparte esa conciencia intuitiva de regla en cuanto hablante competente, sino que quiere entenderlo, tiene que reconstruir aquello en un saber explícito poniendo al descubierto las reglas conforme a las cuales ha sido producido (1976, págs. 310-11).

Si bien desde la filosofía del lenguaje se ha negado, en ocasiones, sentido alguno a la idea de un saber preteórico presupuesto a los actos de habla (vid. a este respecto, por ejemplo, la crítica de Y. Bar-Hillel, 1973, págs. 78), en el contexto de la pragmática universal de Habermas alude a un tipo de conocimiento de imposible fundamentación. Los intentos de reconstruirlo y formular un cuerpo de reglas que rijan un discurso con pretensión de validez son falibles. El argumento trascendental muestra así su debilidad ya que no parece capaz de suministrar una fundarnentación última infalible y solo afirma la falibilidad de una reconstrucción de la capacidad normativa de los presupuestos de la argumentación (Alexy, 1995, pág. 132). Según 
Habermas debe ser lo suficientemente fuerte, sin embargo, como para fundamentar la pretensión de validez universal de una moral procedimental.

A juicio de Alexy esto es una estimación exagerada del argumento trascendental en el ámbito de la filosofía práctica. Alexy adopta la tesis de la pretensión de corrección como presupuesto pragmático trascendental pero ofrece acerca de la misma una versión débil. En el Postfacio a la edición en castellano de la «Teoría de la argumentación jurídica» reconoce que la posibilidad de éxito del argumento pragmático trascendental depende de su complemento con una premisa empírica: «la de que existe un número tan elevado de personas que tienen un interés en llevar a cabo el discurso no estratégicamente, que para aquellos que quieren dirigirlo estratégicamente merece la pena actuar como si para ellos las reglas del discurso valieran también subjetivamente» (Alexy, 1978, págs. 308-9). La combinación de los argumentos trascendental y empírico encuentran un mayor grado de explicitación en su trabajo «Teoría del discurso y derechos humanos», único de los compilados en el libro «Derecho, razón, discurso» («Recht, Vernunft, Diskurs», 1995, págs. 127-64) que no había sido publicado anteriormente. Alexy se plantea en esta sede la posibilidad de fundamentar los derechos humanos desde la ética discursiva. A este fin ensaya en primer lugar una fundamentación de las reglas del discurso. El siguiente paso ha de consistir en justificar los derechos humanos sobre esta base. En lo que sigue me voy a fijar solo en los argumentos esgrimidos en tomo a la primera tentativa.

\section{II}

La tesis que defiende Alexy se asienta sobre tres pilares:

(a) El argumento trascendental, núcleo del razonamiento de fundamentación y que determina el carácter universal. Éste muestra su debilidad no solo por la falibilidad a la que alude Habermas, sino también porque presenta una validez limitada a los discursos ideales.

(b) El remedio a tal debilidad requiere cerrar el argumento trascendental con la premisa empírica de la maximización individual de la utilidad, tal como aparece expresada en la cita recogida más arriba. En esta vinculación de las tesis kantiana y hobbesiana, Alexy considera predominante a la primera sobre la segunda.

(C) La combinación de las dos tesis referidas solo es posible si concebimos de una determinada manera a los sujetos interesados en la corrección. Sólo bajo la aceptación de esta segunda premisa empírica de carácter antropológico podemos confiar, según Alexy, en que un maximizador puro pueda considerarse vinculado por el resultado del modo trascendental de fundamentación. 
Me centraré a continuación en el contenido de (a) y sólo tomaré en consideración alguno de los argumentos que parece sugerir (b) a la luz de la conexión que (C) establece entre (a) y (b). A modo de conclusión, adelanto ahora que la propuesta de fundamentación que defiende Alexy no parece que subsane las debilidades que afectaban al planteamiento de Habermas, y que, en consecuencia, la validez de las reglas del discurso no se asiente en el conocimiento práctico sino que dependa en buena medida de la libre decisión de los participantes en ese discurso (vid. en este mismo sentido, P. Gril, 1997, págs. 206 y ss.).

En relación al argumento trascendental la interpretación de Alexy consiste básicamente en abrir el existencial callejón sin salida en el que ubicaba Habermas a todo aquel que renunciara a la práctica argumentativa y a la acción encaminada al mutuo entendimiento y al acuerdo. El negro horizonte de la esquizofrenia, y la autodestrucción o el suicidio es dulcificado por medio de la tesis siguiente: Quien a lo largo de su vida no plantea ninguna afirmación y no ofrece ninguna fundamentación no participa de la forma de vida más general al ser humano (Alexy, 1995, pág. 139; en un sentido muy parecido, 1978, pág. 306). Ha de entenderse aquí por «afirmación» aquella que se formula con una pretensión de verdad o corrección, que esta pretensión de verdad o corrección implica una pretensión de fundamentabilidad, y que ésta pretensión de fundamentabilidad implica a su vez un deber prima facie de fundamentar cuando se es requerido a ello. La emisión de una afirmación significa así entrar en el campo de la argumentación y el compromiso con las reglas del discurso que expresan el ideal liberal de autonomía y universalidad.

Interesa aquí, sin embargo, dilucidar dos cuestiones, asociadas al argumento trascendental planteado en la tesis (a): (a') en qué sentido puede resultar necesario plantear afirmaciones; y (a") en qué sentido cabe entender que las reglas del discurso especifican condiciones de posibilidad para el entendimiento y el acuerdo, y se muestran constitutivas del significado que atribuimos a la noción de «afirmación».

(a') Respecto de la primera cuestión apuntada ahora, Alexy pretende mostrar cómo la aceptación del postulado universalista del argumento trascendental no es inevitable. A lo que signifique «participar de la forma de vida más general al ser humano» no hay por qué asociar un deber de argumentar en todo caso y frente a cualquiera; quien, por ejemplo, detenta fuerza o poder puede reclamar el cumplimiento de aquello que exige y no justificar su demanda frente a quien o quienes están en una posición de debilidad. Probablemente sí tenga que hacerlo, sin embargo, frente a sus socios o allegados. Con ello ya podemos considerar que participa de esa forma de vida consustancial al ser humano. La flexibilización del argumento trascendental 
elige así un punto medio entre dos extremos: abandona la premisa acerca de que el acuerdo basado en el entendimiento sea la finalidad propia de todo discurso y rechaza a su vez la ausencia de alternativas que Habermas afirmaba respecto de la práctica argumentativa. De acuerdo con Alexy lo que se requiere es que ésta surja frente a alguien y en alguna situación o contexto posible (1995, pág. 140). Lo que queda del argumento trascendental después de debilitarlo de esta forma es todavía, altamente significativo: todo sujeto tiene una capacidad para formular afirmaciones, cuestionarlas y justificarlas y lo que se requiere es el desenvolvimiento de esta capacidad en alguna relación o situación imaginable, es decir, el apoyo de una praxis mínima.

Lo que resulta de una tal reformulación no parece que pueda satisfacer los requerimientos de una fundamentación trascendental. Como se ha dicho, la propuesta se construye sobre el presupuesto de una capacidad para la práctica argumentativa cuyo ejercicio mínimo (de tiempo en tiempo y respecto de algunas personas) se corresponde con una forma de vida común o general a los seres humanos. Así planteado ello implica que, de la misma manera, los individuos cuentan con una capacidad similar para practicar también de vez en vez y en el contexto de ciertas relaciones el engaño, la manipulación, la coacción, etc. El reconocimiento explícito de que este tipo de prácticas están instaladas de hecho en los actos de habla y que, en consecuencia, el sujeto cuenta con dos tipos de capacidad a la hora de construir su discurso, una orientada al entendimiento y al acuerdo y la otra no, requiere, si lo que se lo que se defiende es que solo la primera de ellas se corresponde con una cierta forma de vida que le es propia, la formulación de una tesis normativa adicional: que la finalidad, la idea de telos referida al lenguaje ha de consistir en la búsqueda del entendimiento y el acuerdo. Mientras esto no se produzca no parece posible desentrañar en qué específico sentido pueda aparecer como algo necesario efectuar afirmaciones y fundamentarlas. Ahora bien, planteada en estos términos, da la impresión de que lo que se nos ofrece es una fundamentación puramente empírica de las reglas del discurso expresada a través de una regla que establece una relación medio-fin. El discurso de la teoría del discurso podría así enunciarse por medio de una suerte de regla técnica: sólo quienes estén interesados en la consecución de un acuerdo que pueda ser aceptado como el resultado de un proceso de entendimiento, es decir sólo quienes estén interesados en la corrección, deben respetar las reglas del discurso (P. Gril, 1997, págs. 210-11). El cumplimiento de éstas es algo que pertenece, por tanto, al ámbito de lo que el sujeto puede decidir. Y su decisión vendrá determinada por la valoración que lleve a cabo entre los fines alternativos a los que puede encaminar sus actos de habla, ya que no parece que pueda defenderse satisfactoriamente 
la idea de que es el propio lenguaje, sino una determinada forma del lenguaje, la que podría servir de fundamento a una ética discursiva.

Por otra parte tampoco está exento de problemas el sentido que, en el presente contexto, debamos atribuir a la idea de «forma de vida más general al ser humano». Bajo la noción de «forma de vida», Wittgenstein, entendió una praxis común a la vida humana, que constituye la base de los diversos juegos del lenguaje, y que se caracteriza por determinadas reglas y convicciones fundamentales. Esta idea, como es sabido, juega un papel clave a la hora de comprender el punto de vista moral que parece incluir la filosofía wittgensteniana. La expresión de juicios de valor, las elecciones éticas, al igual que todo juego del lenguaje está basado en la acción, es decir, en actos que por hallarse ligados exclusivamente a nuestra forma de vida estarían, en última instancia injustificados. Solo en el marco de las reglas que definen una forma de vida, cualesquiera que éstas sean, pueden encontrar justificación nuestros juicios de valor pero no hay nada externo, ninguna pauta o medida, con arreglo a la cual y de una vez para siempre, podamos evaluar aquellos. El juego ofrece pautas de justificación, pero el juego mismo no puede ser justificado: «Si he agotado las justificaciones he alcanzado el lecho de rocas y mi azada se rompe. En tal caso me siento inclinado a decir: "Esto es simplemente lo que hago"» (Wittgenstein, 1953, par. 217). De ahí que resulte imposible todo intento de contar con una justificación racional entre formas de vida. Quien pretenda atraer a otro a su posición podrá recurrir a la persuasión, no a la fundamentación: «Lo que ha de ser admitido, lo dado, son -se podría decir- las formas de vida» (1953, par. 226).

Desde luego no es éste el concepto de forma de vida que maneja Alexy. Si se considera que hay distintas formas de vida humana y se acepta la tesis de qué éstas no pueden ser fundamentadas ni criticadas, se está obligado a abandonar la idea de la universabilidad del discurso moral (Alexy, 1978, pág. 68). Esta constatación le lleva a dotar de un sentido radicalmente diferente a la wittgensteniana noción de forma de vida. Tanto en la «Teoría de la argumentación jurídica», como en el ensayo "Teoría del discurso y derechos humanos», Alexy reconoce que la expresión «forma de vida más general al ser humano» no pretende ocultar el hecho de que existen formas de vida concretas radicalmente diferentes. Sí pretende expresar, sin embargo, que esas formas de vida contienen necesariamente universales de la teoría de la argumentación que pueden ser expresados por medio de las reglas del discurso. Y aunque se dé la circunstancia de que ofrezcan poco apoyo debido, sugiere Alexy, a la existencia de tabúes, tradiciones, terror o manipulación que puedan darse en la realidad, aquellos universales sólo desaparecerían del todo si los miembros de una forma de vida perdieran completa y definitivamente la capacidad de plantear seriamente la cuestión 
«¿por qué?». De esta forma el argumento de la forma de vida es traído como un elemento más en la fundamentación de las reglas del discurso para reforzar el carácter universal de éstas: «las reglas del discurso no definen por ello una forma de vida particular, sino algo que es común a todas las formas de vida, sin perjuicio del hecho de que ese algo resulte válido en dichas formas de vida en medida muy distinta» (1978, pág. 306; 1995, pág. 141). La función que desempeña no es ya la de fijar los límites de una racionalidad necesariamente circunscrita a una particular forma de vida, como en la originaria versión de Wittgenstein, sino la de mostrar la existencia de un potencial de razón («Vernunftpotential») que excluye la posibilidad de «diferencias antropológicas resistentes al discurso entre los hombres» (Alexy, 1989, pág. 114). Puede así decirse que la utilización que hace Alexy del concepto de «forma de vida», en lugar de conducimos a afirmar la validez relativa del discurso moral, da fe de una metaética cognoscitiva. Pretende aclaramos aspectos de la naturaleza humana y en esta medida, como él mismo reconoce, sitúa a la teoría del discurso en la tradición del derecho natural (Alexy, 1995, pág. 141).

La idea de forma de vida establece, en última instancia, el momento decisivo de la preferencia racional por la teoría del discurso. En el caso de Alexy, como es sabido, se postula con un carácter universal a partir del ejercicio de una praxis mínima que se hace corresponder con una capacidad inherente a la naturaleza humana. Si esto es una interpretación correcta no parece fácil eludir el defecto lógico de derivar enunciados normativos a partir de premisas fácticas, aun cuando Alexy nos recuerde, en este mismo contexto, que el argumento trascendental sostiene que esa práctica en la que todos tomamos parte, aun cuando sea de forma rudimentaria, es una reconstrucción hecha desde el punto de vista del participante.

Tampoco parece claro que la determinación de una cierta forma de vida, aunque se la dote de un contenido sustantivo tan reducido como lo hace Alexy, pueda ser incluida en una propuesta dirigida a fundamentar el argumento de la pretensión de corrección construida desde la perspectiva del participante. Como sostiene Weinberger (1983, pág. 213), la referencia a la idea de forma de vida parece que sólo puede ser traída por quien es observador y está en condiciones de determinar aquellos aspectos que considera pueden convertir en plausible la elección de aquella como marco de la argumentación racional, pero la forma de vida no es un argumento racional en el proceso mismo de fundamentación. Parecerá inapropiado que quienes participan en el discurso y aducen razones pretendan fundamentar la solidez de éstas alegando simplemente que se corresponden con su forma de vida. Aquellos aspectos que contribuyen a definir una forma de vida, aunque ésta sea concebida como la más general, parece que son susceptibles, en 
principio, de ser cuestionados, a no ser que se estipule que se corresponden con una visión ontológica del ser humano.

(a") La segunda cuestión asociada al argumento trascendental y que más arriba proponía abordar tenía que ver con el sentido que cabe atribuir a la idea acerca de que las reglas discursivas especifican condiciones de las que depende la posibilidad del entendimiento y se muestran así constitutivas del significado que hayamos de atribuir a los actos de habla.

Como es sabido, en la obra de Alexy la pretensión de corrección que se considera inherente a los actos de habla regulativos, establece la conexión conceptual entre el derecho y la moral. Su posición a este respecto creo que queda bien reflejada en el siguiente texto que, a manera de recordatorio de nociones ya expuestas páginas atrás, me permito transcribir: "La teoría de la pretensión sostiene que las normas jurídicas individuales y las decisiones judiciales, así como el sistema jurídico en su totalidad, necesariamente tienen una pretensión de corrección. Los sistemas de normas que no tienen esta pretensión, implícita o explícitamente, no son sistemas jurídicos. Por el momento, la teoría de la corrección es de carácter definitorio. Los sistemas jurídicos que tienen esta pretensión, pero no la satisfacen, son sistemas defectuosos. En este sentido la teoría de la pretensión es calificativa. La teoría de la pretensión juega un papel exclusivamente calificativo en el caso de las normas individuales y de las decisiones judiciales. Éstas son jurídicamente defectuosas cuando no tienen, o no satisfacen, la pretensión de corrección» (1989, págs. 51-2).

De esta forma el artículo constitucional que dijera: «X es una república soberana, federal e injusta», sería un artículo defectuoso. Un tipo de defecto que no podría ser considerado de carácter exclusivamente técnico, o moral, o convencional, sino que se trataría de un defecto conceptual, en el sentido de que contradice la necesaria relación que se establece entre el acto de dictar una constitución y una pretensión de corrección o justicia (Alexy, 1989, págs. 52-3. En contra de que este tipo de enunciado sea contradictorio, E. Bulygin, 1993, págs. 19-24.). A un similar tipo de contradicción se refiere Garzón Valdés en relación a frases del tipo: «Creo en la legitimidad de mi sistema, pero es ilegítimo», o «creo en la legitimidad de mi sistema, pero no pretendo que lo sea» (1990, pág. 121). Es decir, que las autoridades y funcionarios se contradirían a ellos mismos si sostuvieran que la ética no juega ningún papel en el concepto de validez de las normas frente a las que adoptan un punto de vista interno.

También puede ser traída aquí la posición de P. Soper quien establece el vínculo conceptual entre el derecho y la moral sobre la base de la imputación a todo hablante de una intención de sinceridad necesariamente referida a sus actos de habla consistentes en ofrecer explicaciones y justificaciones. 
Dado que los sistemas sociales organizados pueden ser creados y mantenidos por una diversidad de motivos que no tiene por qué suponer la existencia de una obligación moral, tales como el miedo, la inercia, la tradición o un cuidadoso cálculo de intereses egoístas (Hart, 1958, p. 17), el reconocimiento de estas posibilidades empíricas traslada la discusión de la tesis de la vinculación al único nivel posible: el de la definición. Es desde esta sede, conceptual, desde la que «(s)e debe explicar por qué los sistemas jurídicos que no incluyen una creencia oficial en la justicia no cuentan como sistemas jurídicos» (Soper, 1984, pág. 70). La mayor fuerza de este nivel de análisis respecto del puramente empírico se muestra al establecer una analogía con la institución de las promesas. Existe aquí «una conexión conceptual entre un concepto (promesa) y la creencia en una pretensión moral (una obligación de respetar las promesas)... Lo que no se puede hacer es realizar una promesa y simultáneamente negar la intención de respetarla, o negar la creencia en una obligación de respetar las promesas. En semejante caso el destinatario de la promesa entenderá que no se realiza promesa alguna sino, a lo sumo, el enunciado de la intención de realizar una acción en el futuro» (págs. 70-1). La remisión a la virtualidad de una teoría del discurso aparece de forma inequívoca, aun cuando en su presentación y grado de elaboración tenga poco en común con las tentativas de Habermas o Alexy (en este sentido, Prieto Sanchís, 1994, pág. 239). Su función queda establecida en los siguientes términos: «Los individuos disidentes deben tener asegurado un derecho al discurso, un derecho a insistir en revisar la evidencia de la buena fe en la creencia, en la única forma en la que se puede evaluar la sinceridad: esto es, mediante la comunicación, el diálogo, el intercambio y el debate» (Soper, 1984, pág. 202).

Resulta evidente que los enunciados que se corresponden con los tres planteamientos descritos desconocen toda pretensión de corrección y que, en este sentido podría aplicarseles el austiniano calificativo de «desafortunados» («infelicitous»), (R. Siltala, 1990, pág. 166). Pero lo que está en juego es, sin embargo, si la contradicción performativa que se detecta en los aludidos enunciados, esto es, la existencia de una incompatibilidad entre lo que se prescribe a través de un acto de habla regulativo y las supuestas reglas que rigen tal acto de habla invalidan éste al mostrar su incorrección moral. Creo que la defensa de esta posición pasa de forma necesaria por la afirmación de que ciertas estructuras lógicas, semánticas y pragmáticas de la racionalidad normativa son $a$ priori válidas $\mathrm{y}$, por tanto, poseen un carácter trascendental (O. Guariglia, 1996, pág. 156). Algo que Habermas rechaza respecto del planteamiento de Apel, y que explicaría probablemente el progresivo acercamiento de Alexy a los postulados de una pragmática trascendental y no universal (1978, «Postfacio» a la trad. cast. 1989, pág. 305). Dicho 
con otras palabras, se pretendería un reconocimiento moral a partir del reconocimiento formal de aquellas estructuras.

Debe entonces interpretarse que la contradicción performativa tiene lugar cuando se vulnera la regla que prescribe argumentar racionalmente, regla que desde la perspectiva pragmático trascendental debe admitirse «ya siempre» («immer schon»), es decir, como presupuesto básico de la argumentación (W. Kuhlmann, 1985, pág. 82). Y que a esta estructura previa pertenece igualmente un núcleo de moralidad cuyo «despliegue» en enunciados normativos solo es posible a partir de esa regla primera o presupuesto de la argumentación. De esta forma debemos entender que las normas que fundaran la exigencia de alcanzar un acuerdo, de cumplir las condiciones que permitan un mayor grado de realización de una situación ideal de diálogo, etc., están incluidas o son derivables de aquella regla suprema y dan cuerpo a una ética cognoscitiva. Quien desde una posición escéptica negara entonces validez a la prescripción «iArgumenta racionalmente!» estaría enunciado una proposición, que desde el modo trascendental de argumentación, sería necesariamente falsa. Ahora bien, ¿de qué tipo de falsedad se trataría? Probablemente tendríamos que aceptar, como plantea E. Hilgendorf (1995, págs. 193 y ss.), que los candidatos posibles a esta respuesta son básicamente los siguientes:

(i) en primer lugar, podría uno preguntarse si no se trata de una falsedad de tipo empírico. Obviamente, el defensor de una concepción pragmático trascendental de la argumentación rechazaría esta interpretación. Si se considera que un enunciado $p$ cuyo contenido consiste en negar validez a las reglas de la argumentación es fácticamente (empíricamente) falso, entonces la demostración de $\neg p$ (no $p$ ) supone que, por medio de una investigación empírica podríamos llegar a comprobar que las reglas de la argumentación valen para todo hablante. En efecto, la pragmática trascendental no puede admitir esto. Ya que el argumento pierde su carácter apriorístico, no puede hablarse de un contenido necesariamente verdadero. Desde la perspectiva adoptada todo intento de indagación empírica dirigida a demostrar la verdad de $(\neg p)$ es tachado de irrelevante y erróneo.

(ii) Otra posibilidad estriba en considerar la negación de las reglas de argumentación como un caso de falsedad lógica. Si el enunciado $p$ que emite el escéptico es lógicamente falso, su negación sería, por tanto, necesariamente verdadera. Tiene razón Kuhlmann, arduo defensor de una fundamentación pragmático trascendental del discurso, al afirmar que estaríamos entonces, como ocurre con todo enunciado lógicamente verdadero, ante una tautología vacía de contenido que nada aportaría a la fundamentación del discurso (1985, pág. 85$)$. 
(iii) El partidario de una fundamentación pragmático trascendental se ve así abocado a afirmar que la contradicción planteada por el enunciado $p$ que formula el escéptico es una contradicción de un tipo especial que, como es sabido, califica de performativa. Resulta significativo a este respecto, como observa Hilgendorf, (1995, pág. 193) que autores como Apel o Kuhlmann, defensores de una genuina concepción pragmático trascendental, no recurran al significado que en el ámbito de la filosofía del lenguaje se le atribuye al concepto de «contradicción performativa», y admitan que en el contexto de una fundamentación pragmático trascendental ésta alude a una suerte de «inconsistencia existencial» (Kuhlmann, 1985, págs. 89 y 230), expresión que toman prestada del análisis que el lógico J. Hintikka hace del argumento cartesiano "Cogito, ergo sum» (1962, págs. 3-32). De acuerdo con la interpretación que este autor lleva a cabo de las premisas del razonamiento de Descartes hubiera sido imposible por autocontradictorio negar la propia existencia, o que el propio Descartes afirmara: «Descartes no existe». Un enunciado de este tipo representa, según Hintikka, un caso de la mencionada «inconsistencia existencial» (págs. 8-9). Ahora bien, ¿puede reclamarse de la contradicción planteada un tipo de falsedad específica, o se trata simplemente de un supuesto de falsedad empírica? Si tomamos en cuenta que en relación al ejemplo utilizado la falsedad del enunciado es susceptible de ser advertida sin más tanto por el propio hablante (Descartes) como por todo oyente que se percatara de quién era en realidad el que lo formulaba, no parece que quepa otra posibilidad que optar por la segunda de las interpretaciones. Es en este sentido, en el que Hilgendorf (pág. 196), creo que con razón, critica por inadecuado que el argumento de la inconsistencia existencial, traído por Hintikka, pueda prestar apoyo a la pragmática trascendental y lo que demostraría una vez más que la llamada contradicción performativa, en el marco de este modo de fundamentación, es una noción insuficientemente aclarada.

Quizá convenga recuperar ahora la idea a la que aludía más arriba, acerca de cómo en el caso de la teoría de Alexy la flexibilización del argumento trascendental conducía al reconocimiento de dos tipos de capacidad a la hora de construir su discurso, una orientada al acuerdo logrado por medio de un entendimiento que las reglas del discurso hacen posible, y otra para practicar, también ocasionalmente, el engaño, la manipulación, y la coacción. El cumplimiento de las reglas del discurso era algo que quedaba condicionado al interés del sujeto en el argumento de la corrección y la opción por el desempeño de esta capacidad algo que pertenecía al ámbito de lo que libremente podía decidir. En suma, no parecía que pudiera defenderse satisfactoriamente la idea de que es el propio lenguaje, sino una determinada forma del mismo la que podría servir de fundamento a la ética discursiva. Y 
a propósito, ahora, de la contradicción performativa los argumentos recordados sugieren que ésta solo puede darse en tanto que el participante en el discurso decida comportarse éticamente, es decir, con arreglo a las reglas que Alexy propone. O, como prefería Habermas, siempre que se parta de un determinado, intuitivo, y no justificado saber preteórico; por supuesto aquel que se corresponde con una práctica argumentativa definida por la pretensión de corrección.

Me parece así acertado el punto de vista defendido por O. Guariglia acerca de que la supuesta consecuencia moral que se deriva de la contradicción performativa en que incurre el hablante cuando no admite previamente las reglas que regulan el diálogo quedaría circunscrita a la interioridad del propio hablante, cuya conciencia moral al cometer la contradicción se despertaría para indicarle que ésta no es moralmente admisible. En cuanto acto de conciencia se tratará, por tanto de un acontecimiento subjetivo y contingente que será percibido por unos pero no por otros: «Para el hombre moral, la comisión de una contradicción performativa le resultará intolerable; el inmoral, en cambio, la atesorará como un recurso más para embaucar a los ingenuos. Tanto el uno como el otro, sin embargo, no tendrán para guiarse más que criterios intuitivos de cuál es la acción moralmente correcta ya que... la contradicción performativa per se no ofrece ningún criterio moral» (1996, pág. 157).

De acuerdo con lo expuesto hasta ahora no creo que pueda concederse a Alexy haber resuelto satisfactoriamente su pretensión de dotar de una fundamentación última, en todo o en parte, a las reglas del discurso. Los esfuerzos de una concepción pragmático trascendental por encontrar una salida a los problemas que plantea el trilema de Münchhausen no parecen tener éxito. Habermas pretendía una ruptura en el proceso de fundamentación mostrando que frente al entendimiento y la comunicación no hay alternativa posible ya que son exponentes de una práctica que se halla en la base de todo comportamiento humano. Que esta finalidad sea inherente a los discursos ideales parece algo inatacable. Pero dado que en los discursos reales los actos de habla pueden orientarse hacia fines diferentes al sugerido por Habermas, parece que sólo en el marco conceptual de la razón comunicativa podrá afirmarse que la única alternativa racional es el habla y la acción orientada al entendimiento y el acuerdo. Dicho de otra forma, sólo una determinada forma del lenguaje, y no el lenguaje mismo, podría servir a la fundamentación de principios éticos (H. Scheit, 1987, pág. 363). En el caso de Alexy, el debilitamiento del argumento trascendental reducía esa carencia de alternativas de las reglas del discurso a las ocasiones en que los individuos, en el transcurso de sus vidas, recurran a la práctica argumentativa. 
Un tal grado de indeterminación no parece que pueda proporcionar una justificación adecuada de la validez universal de las reglas discursivas.

(b). Me referiré, para finalizar, a la tesis (b) de la fundamentación del discurso que propone Alexy, es decir, a la premisa empírica. Con independencia de que resulte o no plausible la sorprendente combinación de un kantiano modo trascendental de argumentación con una ponderación de intereses de origen inequívocamente hobbesiano, no parece que con ello se avance algo en el terreno de la fundamentación. Las consideraciones acerca de la existencia de un interés de los individuos en la corrección aparecen, en la obra de Alexy, en relación a dos supuestos diferentes: (i) debe presuponerse un tal interés que explique por qué quienes reconocen la corrección de las reglas que rigen el habla las aplican en la práctica. Así, según Alexy, «si se presupone este interés, entonces el argumento pragmático trascendental puede fundamentar la validez de las reglas del discurso en lo referente a sus consecuencias en el campo de la acción» (1978, pág. 307), y (ii) el interés, al que ya se ha aludido páginas atrás, de aquellos que orientan su discurso estratégicamente en actuar como aceptantes comprometidos con las reglas del discurso ya que se presume que una mayoría de sujetos se inclinarán por discursos no estratégicos (pág. 309). En ambos casos la ponderación de intereses da por supuesta la corrección objetiva de las reglas del discurso y da por bueno, en consecuencia el argumento pragmático trascendental de fundamentación. Desde este punto de vista no podría hablarse entonces de contradicción entre los diferentes elementos (kantiano y hobbesiano) empleados en la argumentación (en un sentido crítico de esta compatibilidad, M. Atienza, 1991, pág. 220). Dejaría intactas, sin embargo, las críticas que se han dirigido respecto de una fundamentación pragmático trascendental.

Por otra parte tampoco resulta convincente que el argumento empírico cierre de manera satisfactoria el intento de fundamentación que propone Alexy (1978, pág. 308). Tanto en el caso de la existencia de un interés preexistente en el valor de la corrección, como en el supuesto de una presunción en favor de la maximización de la utilidad por medio del respeto a las reglas del discurso (admitiendo que se dé una tal relación medio-fin), el cumplimiento de las reglas discursivas depende una vez más del acto de voluntad que representa la toma de una decisión. Por ello, en tanto que empírica la premisa puede ser tan cierta como falsa, es decir que podemos suponer también la existencia de individuos no interesados en la pretensión de corrección de la ética discursiva, o la de quienes no estén interesados en maximizar su propia utilidad. Respecto de ellos no parece que pueda afirmarse el carácter vinculante de las reglas del discurso (P. Gril, 1997, pág. 216).

Las reglas del discurso, o al menos las denominadas por Alexy, reglas de razón, no creo que puedan ser identificadas, contrariamente a lo pretendido 
por su autor, con categorías universales de la práctica argumentativa, sino en todo caso como expresivas de lo que puede ser una cierta representación de lo que es la discusión racional. $\mathrm{O}$ de un determinado tipo histórico de derecho, a saber, el derecho moderno occidental con el que se alcanza por vez primera «un sistema de procedimientos jurídicos diferenciados y especializados: procedimientos legalmente regulados para la creación de normas jurídicas y para la aplicación del derecho» (K. Tuori, 1988, pág. 49). Este cognoscitivismo débil que subyace a los intentos de vincular el derecho a la moral por medio del argumento de la pretensión de corrección o del llamado argumento de la creencia moral (R. Caracciolo, 1994, págs. 97-110), aclara por qué queda sorprendentemente abierta la cuestión acerca de qué contenidos de moralidad son los requeridos para establecer tal vinculación (L. Prieto, 1997, pág. 76). La inexistencia de criterios para determinar la validez objetiva de un determinado principio moral equivale a afirmar que cualquier norma o prescripción es un principio moral, o que la creencia de un determinado sujeto $x$ no forma parte prima facie, como sostiene R. Caracciolo, del concepto de norma o de principio moral (1994, pág. 108; en un sentido parecido, E. Bulygin, 1998, págs. 222/3). El ejemplo propuesto por Alexy, que atribuye juridicidad a un orden depredatorio cuando surge una «pretensión de corrección» que él identifica meramente con la existencia de algunas reglas generales y una mínima seguridad en su aplicación pero en el que persiste como pauta de comportamiento el propósito de la dominación y la explotación, parece confirmar lo defendido por Caracciolo. La pretensión de que un sistema es correcto aun cuando haya que recurrir al engaño o la manipulación para obtener aceptación no parece argumento suficiente para establecer la tesis de la vinculación conceptual entre el derecho y la moral. Claramente, la justicia se aproxima aquí la idea de seguridad. La flexibilización, anteriormente criticada, de los presupuestos de la teoría habermasiana y la consiguiente amplitud discursiva permite que la exigente cuestión de la justicia se convierta, para los gobernantes injustos, en un más cómodo problema de seguridad o de moral interna del derecho, en recuerdo de las tesis de Fuller. R. Siltala ha puesto de manifiesto cómo en relación a normas aisladas en las que la conexión entre derecho y moral que defiende Alexy tiene un carácter calificativo, la sombra de Fuller parece estar presente por la analogía que cabe establecer con la idea de una moral interna del derecho que si es vulnerada, en tanto que moral de aspiración y no de deber, afecta a su perfección como norma pero no la priva de validez jurídica (Siltala, 1990. Pág. 164).

Probablemente todo lo anterior tenga que ver con lo observado por Soper acerca de cómo en cierto sentido positivistas y no positivistas llegan a construir teorías divergentes partiendo, sin embargo, de presupuestos en buena medida similares acerca de la relación entre derecho e ideal de certeza. 
Mientras el positivismo encontraría en el punto de vista externo el presupuesto epistemológico desde el que rechazar la incerteza, el no positivismo sugiere la alternativa moral. Este enfoque moral convierte a la cuestión de la relación entre derecho y seguridad o predecibilidad en una cuestión de ética sustantiva. Este cognoscitivismo moral es la piedra angular de toda definición de derecho que rebasa los límites del derecho positivo y quiere encontrar allí un mínimo de seguridad. Desde esta perspectiva cabría constatar, como señala A. García Figueroa una muestra de la insuficiencia que aqueja al antipositivismo de Alexy; su teoría obtiene esa seguridad en la razón práctica porque en buena medida ésta se debilita en sus contenidos hasta asimilarse a la propia seguridad (1997, pág. 505).

El argumento, que parece concluirse de la propuesta de Alexy y no sé si de la defendida por Garzón Valdés, de que la mera creencia en un cierto principio, con independencia de su contenido, puede ser suficiente para su consideración como un principio moral es coherente con la fundamentación débil que Alexy proporciona a las reglas discursivas que propone, pero incompatible con la idea de corrección moral. Si esto era lo que perseguía Alexy, desde luego las expectativas generadas con la expresión elegida («pretensión de corrección») son muy superiores a los logros obtenidos.

\section{Bibliografía}

Alexy, R. (1978): Teoría de la argumentación jurídica, trad. de M. Atienza, I. Espejo, Centro de Estudios Constitucionales, Madrid 1989.

Alexy, R. (1989): Sobre las relaciones necesarias entre el derecho y la moral, trad. de P. Larrañaga, en R. Alexy: Derecho y razón práctica, Fontamara, México 1993, págs. 37-58.

Alexy, R. (1995): Recht, Vernunft, Diskurs, Suhrkamp, Frankfurt a. Main.

Atienza, M. (1991): Las razones del derecho. Teorías de la argumentación jurídica, Centro de Estudios Constitucionales, Madrid.

Bar-Hillel, Y. (1973): On Habermas' Hermeneutic Philosophy of Language, en Synthese 26, págs. $1-12$.

Bulygin, E. (1993): Alex und das Richtigkeitsargument, en Aarnio, y otros (comps.): Rechtsnorm und Rechtswirklichkeit, Duncker \& Humblot, Berlin, págs. 19-24.

Bulygin, E. (1998): ¿Hay vinculación necesaria entre derecho y moral?, en R. Vázquez (comp.): Derecho y moral. Ensayos contemporáneos, ed. Gedisa, Barcelona, págs. 214-223.

Caracciolo, R. (1994): L'argomento della credenza morale, en Analisi e diritto, Giappichelli ed., Turín, págs. 97-110.

García Figueroa, A. (1997): El no positivismo principialista. Las teorías de R. Dworkin y R. Alexy, tesis doctoral, actualmente en prensa, Centro de Estudios Políticos y Constitucionales. 
Garzón Valdés, E. (1990): Algo más acerca de la relación entre derecho y moral, en Doxa, $\mathrm{n}^{\circ} 8$, págs. 119-30.

Garzón Valdés, E. (1996): Derecho y moral, en Enciclopedia Iberoamericana de Filosofía, tomo II; ed. Trotta, C.S.I.C., B.O.E.; Madrid, págs. 397-424.

Gril, P. (1997): Alexys Version einer traszendental-pragmatischen Begründung der Diskursregeln im Unterschied zu Habermas, en ARSP, vol. 83, págs. 206-216.

Guariglia, O. (1996): Moralidad. Ética universalista y sujeto moral, Fondo de Cultura Económica, Buenos Aires.

Habermas, J. (1972): Teorías de la verdad, en Habermas, J.: Teoría de la acción comunicativa: complementos y estudios previos, ed. Cátedra, Madrid 1994.

Habermas, J. (1976): ¿Qué significa pragmática universal?, en Habermas, J.: Teoría de la acción comunicativa: complementos y estudios previos, cit. págs. 299-368.

Habermas, J. (1983): Conciencia moral y acción comunicativa, trad. R. G. Cotarelo, ed. Península, Barcelona 1985.

Hart, H.L.A. (1958): Obligación jurídica y obligación moral, trad. J. Esquivel y L. Alfonso Ortiz, UNAM, México 1977.

Hart, H.L.A. (1982): Essays on Bentham, Clarendon Press, Oxford.

Hart, H.L.A. (1983): Essays in Jurisprudence and Philosophy, Clarendon Press, Oxford.

Hilgendorf, E. (1995): Zur traszendentalpragmatischen Begründung von Diskursregeln, en Rechtstheorie, $\mathrm{n}^{\circ} 27$, págs. 183-200.

Hintikka, J. (1962): Cogito, Ergo Sum: Inference or Performance?, en Philosophical Review 71, págs. 3-32.

Kuhlmann, W. (1985): Reflexive Letzbegrimdung: Untersuchungen zur Traszendentalpragmatik, K. Alber, Freiburg-München.

Prieto, L. (1994): P. Soper Una teoría del derecho, en Revista del Centro de Estudios Constitucionales, $\mathrm{n}^{\circ} 18$, págs. 233-242.

Prieto, L. (1997): Constitucionalismo y positivismo, Fontamara, México.

Scheit, H. (1987): Wahrheit, Diskurs, Demokratie, Freiburg-München.

Siltala, R. (1990): Derecho, moral y leyes inmorales, trad. de $\mathrm{M}^{\mathrm{a}} \mathrm{J}_{\mathrm{osé}}$ Añón, en Doxa, $\mathrm{n}^{\mathrm{o}}$ 8, págs. 149-170.

Soper, P. (1984): Una teoría del derecho, trad. de R. Caracciolo, Centro de Estudios Constitucionales, Madrid 1993.

Tuori, K. (1988): Ética discursiva y legitimidad del derecho, trad. de J. Aguiló, en Doxa, nº 5, págs. 47-67.

Weinherger, O. (1983): Logische Analyse als Basis der juristischen Argumentation, en W. Krawietz y R. Alexy, (comps.): Metatheorie juristischer Argumentation, Duncker \& Humblot, Berlin, págs. 159-232.

Wittgenstein, L. (1953): Philosophical Investigations, $3^{\mathrm{a}}$ ed., Maemillan, New York, 1968. 